\title{
Stabilisasi Tanah Pandaan dengan Bitumen untuk Subgrade J alan Raya
}

\author{
Djoko Sulistiono, Sulchan Arifin \& Chomaedhi \\ Laboratorium Uji Material \\ Program Diploma Teknik Sipil FTSP-ITS \\ email: djoko-sulis@ce.its.ac.id, sulchan@ce.its.ac.id, meddy@ce.its.ac.id
}

\begin{abstract}
ABSTRAK
Stabilisasi tanah bertujuan memperbaiki sifat fisik tanah yang semula jelek menjadi lebih baik. Tanah dasar jalan (subgrade) yang jelek bisa diperbaiki sifat fisiknya dengan stabilisasi kimia (butimen). Kondisi tanah dasar yang baik mampu mempertipis lapisan perkerasan di atas, tetapi stabilisasi butimen mempunyai persyaratan berbeda dengan bahan stabilisasi kimia lainnya. Permasalahan, sampai sejauh mana kemampuan butimen sebagai bahan stabilisasi? Metode penelitian laboratorium mengikuti cara Bina Marga, tanah yang akan distabilisasi diambil dari daerah Pandaan J awa Timur untuk ditest Atterberg, test Proktor dan CBR. Kemudian tanah dicampur dengan butimen pada variasi kadar butimen $2 \%$ $3 \%$ 4\% 5\% 6\% untuk kemudian dilakukan test Atterberg, Proktor dan CBR. Selanjutnya dievaluasi perubahan fisik sehubungan penambahan bahan butimen tersebut. Hasil penelitian menunjukkan bahwa tanah Pandaan dalam kondisi asli memenuhi syarat sebagai tanah dasar jalan (subgrade), terlihat dari harga Indeks Plastisitas $(\mathrm{PI})=7,04 \%<\mathrm{PI}$ maximum $=10 \%$ dan $\mathrm{CBR}=11,33 \%>$ CBR minimum $=$ 6\% Tanah Pandaan juga memenuhi syarat distabilisasi butimen karena batas cair $(\mathrm{LL})=23,50 \%<30 \%$ Indeks Plastisitas $(\mathrm{PI})=7,04<12 \%$ dan presentase lolos ayakan no. $200=41,84 \%<50 \%$ Tetapi setelah ditambah butimen ternyata harga LL dan PI menjadi lebih besar / kurang baik. Kemudian harga CBR juga semakin mengecil pada kondisi kering, karena tanah campuran menjadi lebih plastis. Kadar butimen yang paling optimum, bila memang diperlukan stabilisasi butimen, adalah $2 \%$
\end{abstract}

Kata kunci: Stabilisasi, Bitumen, Subgrade

\section{PENDAHULUAN}

Stabilisasi butimen (aspal) merupakan salah satu bentuk stabilisasi kimia, dengan tujuan memperbaiki sifat fisik tanah yang semula jelek, menjadi lebih baik. Tanah yang telah distabilisasi butimen, diharapkan bisa meningkat kekuatannya, serta lebih tahan terhadap perubahan kadar air.

Tanah dasar jalan (subgrade) yang jelek, dapat pula diperbaiki dengan stabilisasi butimen, hanya tanah dasar yang distabilisasi butimen tersebut harus memenuhi persyaratan tertentu sebagaimana diatur dalam Guide to Stabilization in Road Works (1970). Persyaratan tersebut jelas berbeda dengan persyaratan tanah yang distabilisasi dengan kapur, semen. Tanah dasar jalan yang baik mampu mempertipis lapisan perkerasan di atasnya. Permasalahan, sampai sejauh mana manfaat butimen sebagai bahan stabilisasi? Hal ini tentunya terjawab setelah melalui tahap penelitian laboratorium.

\section{DASAR TEORI}

Tanah yang bisa distabilisasi dengan butimen menurut Guide Stabilization in Road Works (1970) harus memenuhi persyaratan tertentu sebagaimana Tabel 1.

Tabel 1. Persyaratan jenis tanah yang dapat distabilisasi butimen

\begin{tabular}{|c|c|c|c|c|}
\hline No. & Persyaratan fisik & $\begin{array}{l}\text { Pasir } \\
(\%)\end{array}$ & $\begin{array}{c}\text { Tanah } \\
(\%)\end{array}$ & $\begin{array}{l}\text { Sand } \\
\text { gravel } \\
(\%)\end{array}$ \\
\hline \multirow[t]{9}{*}{1} & Gradasi saringan & & & \\
\hline & Lolos 11/2" & - & - & 100 \\
\hline & Lolos 1" & 100 & - & - \\
\hline & Lolos 3/4" & - & - & $60-100$ \\
\hline & Lolos 3/16" & $50-100$ & $50-100$ & $35-100$ \\
\hline & Lolos no. 7 & - & - & - \\
\hline & Lolos no. 36 & - & $35-100$ & $13-50$ \\
\hline & Lolos no. 100 & - & - & $8-35$ \\
\hline & Lolos no. 200 & $5-12$ & $10-50$ & $0-12$ \\
\hline 2 & Liquid Limit (\%) & - & $<30$ & - \\
\hline 3 & $\begin{array}{l}\text { Plasticity Index } \\
\text { (\%) }\end{array}$ & $<10$ & $<12$ & $<10$ \\
\hline
\end{tabular}

Sumber: Guide Stabilization in Road Works (1970) 
Tanah berbutir kasar (kurang 50\% lolos ayakan no. 200) cukup berhasil distabilisasi butimen, bila dibandingkan dengan tanah yang berbutir halus (lebih dari $50 \%$ lolos ayakan no. 200). Kemudian salah satu jenis butimen yang bisa dipakai sebagai bahan stabilisasi kimia adalah aspal cut back (cut back butimens). Aspal ini menurut Silvia Sukirman (2003) merupakan jenis aspal cair, yang merupakan campuran asphalt cement dengan bahan pelarut minyak bumi. Aspal cut back berbentuk cair pada temperatur ruang dan berdasarkan pelarutnya, dibedakan atas:

- RC (Rapid Curing cut back), merupakan aspal semen dengan pelarut bensin/ premium.

- MC (Medium Curing cut back), merupakan aspal semen dengan pelarut minyak tanah.

- SC (Slow Curing cut back), merupakan aspal semen dengan pelarut solar.

Bahan-bahan aspal cut back harus memenuhi syarat-syarat teknis, sebagaimana pada Tabel 2, yang dikeluarkan oleh Lembaga Masalah Jalan Departemen PU, khususnya jenis MC-250 sebagai berikut.

Tabel 2. Persyaratan teknis aspal cara MC-

\begin{tabular}{|c|l|c|c|}
\multicolumn{2}{|c|}{ Jenis pemeriksaan } & \multicolumn{2}{c|}{ MC-250 } \\
\cline { 3 - 4 } No. & & Min & max \\
\hline 1 & Viskositas kinetik 60\% & 250 & 500 \\
\hline 2 & Titik nyala ( $\left.{ }^{\circ} \mathrm{C}\right)$ & 65 & \\
\hline 3 & Penetrasi (0,1 mm) & 120 & 250 \\
\hline 4 & Daktilitas (cm) & 100 & \\
\hline 5 & Kelarutan zat CL4 (\%) & 99 & \\
\hline 6 & Pelekatan dalam air (\%) & 80 & \\
\hline 7 & Kadar air (\%) & & 0,20 \\
\hline
\end{tabular}

Sumber: Lembaga Masalah J alan Departemen PU

Penggunaan butimen sebagai bahan stabilisasi harus efisien, karena harganya mahal. Menurut Guide Stabilization in Road Works (1970), untuk material berbutir diperlukan kadar butimen $2 \%$ sampai dengan $5 \%$ Penggunaan Butimen, menurut Punmia (1981) mampu menambah kohesi (binding action) dan mengurangi absorsi air. Tanah yang telah distabilisasi butimen, bisa dipakai sebagai tanah dasar jalan (subgrade), bila indeks plastisitas $(\mathrm{PI})<\mathrm{PI}$ maximum $=10 \%$ dan harga $\mathrm{CBR}>\mathrm{CBR}$ minimum $=6 \%$

\section{METODOLOGI}

Beberapa langkah yang dilakukan dalam studi ini, dimana sebagian besar kegiatannya dilakukan di laboratorium.

- Melakukan test Atterberg, test saringan, test CBR dan test pemadatan untuk tanah asli (sebelum distabilisasi).

- Tanah asli dan aspal cut back dicampur dengan variasi kadar aspal cut back $2 \%$ $3 \% \quad 4 \% \quad 5 \% \quad 6 \%$ untuk selanjutnya dilakukan test yang sama seperti sebelum distabilisasi. Tetapi untuk CBR diberikan variasi pukulan 10 kali, 30 kali dan 65 kali.

- Menganalisa hasil test sebelum dan sesudah stabilisasi butimen untuk mengetahui manfaat pemberian bahan butimen (aspal cut back MC-250) tersebut. Sehingga bisa dimanfaatkan sebagai tanah dasar (subgrade) jalan raya.

\section{HASIL DAN PEMBAHASAN}

Penelitian tanah Pandaan di laboratorium sebelum dan sesudah stabilisasi,

memberikan hasil sebagaimana Tabel 3 dan

Tabel 4 berikut ini:

Tabel 3. Hasil Test Atterberg dan Test Proktor

\begin{tabular}{|c|c|c|c|c|c|}
\hline $\begin{array}{c}\text { Kadar } \\
\text { butirmen } \\
\text { MC-250 } \\
(\%)\end{array}$ & LL & $\mathrm{PL}$ & $\mathrm{PI}$ & $\begin{array}{c}\text { Wlopt } \\
(\%)\end{array}$ & $\begin{array}{c}\gamma \mathrm{d} \\
(\mathrm{gr} / \mathrm{cc})\end{array}$ \\
\cline { 2 - 6 } & & 16,46 & 7,04 & 13,80 & 1,84 \\
\hline 0 & 23,50 & 20,95 & 9,85 & 12,12 & 1,96 \\
\hline 2 & 30,70 & 20,95 & \multicolumn{2}{|c|}{ Proktor } \\
\hline 3 & 30,35 & 20,03 & 10,32 & 12,61 & 1,93 \\
\hline 4 & 29,80 & 18,81 & 10,99 & 13,22 & 1,89 \\
\hline 5 & 28,90 & 17,15 & 11,55 & 13,81 & 1,84 \\
\hline 6 & 27,90 & 15,95 & 11,95 & 14,22 & 1,81 \\
\hline
\end{tabular}

Tabel 4. Hasil Test CBR Tanah Pandaan

\begin{tabular}{|c|c|c|c|c|c|c|}
\hline \multirow{2}{*}{$\begin{array}{c}\text { Kadar } \\
\text { butirmen }\end{array}$} & \multicolumn{6}{|c|}{ Harga CBR (\%) } \\
\cline { 2 - 7 } $\begin{array}{c}\text { MC-250 } \\
(\%)\end{array}$ & $10 \mathrm{x}$ & $30 \mathrm{x}$ & $65 \mathrm{x}$ & $10 \mathrm{x}$ & $30 \mathrm{x}$ & $65 \mathrm{x}$ \\
\hline & \multicolumn{5}{|c|}{ Basah } & \multicolumn{3}{c|}{ Kering } \\
\hline 0 & 3,80 & 11,33 & 13,67 & 27,33 & 53,33 & 54,00 \\
\hline 2 & 4,20 & 24,00 & 18,33 & 24,00 & 42,67 & 45,00 \\
\hline 3 & 4,50 & 26,00 & 21,00 & 17,00 & 22,00 & 28,67 \\
\hline 4 & 7,23 & 13,67 & 13,67 & 16,33 & 17,67 & 18,33 \\
\hline 5 & 6,50 & 12,00 & 10,00 & 9,50 & 12,00 & 12,33 \\
\hline 6 & 5,67 & 8,83 & 8,50 & 9,33 & 9,00 & 9,50 \\
\hline Sumber: & \multicolumn{3}{|c|}{ Soekisw0, Harry S dan Heru S (1987) } \\
\hline
\end{tabular}


Melalui test Atterberg tanah asli, batas cair (LL) adalah 23,50\% < 50\% plastisitas rendah, batas plastis $(\mathrm{PL})=16,46 \%$ dan Indeks Plastisitas $(\mathrm{PI})=7,04 \%<\mathrm{PI}_{\max }=10 \%$ Melalui test saringan, prosentase lolos saringan no. 200 adalah 41,84\% < 50\% maka tanah berbutir kasar. Melalui test CBR laboratorium tanah asli diperoleh harga pada 30 pukulan $\mathrm{CBR}=11,33 \%>\mathrm{CBR}_{\min }=6 \%$ Melalui test proktor, diperoleh kadar air optimum $\left(\mathrm{WC}_{\mathrm{opt}}\right)=13,80 \%$ dengan $\gamma$ dry $\max$ $=1,84 \mathrm{gram} / \mathrm{cc}$.

Berdasarkan data di atas, maka tanah asli termasuk tanah berbutir kasar, plastisitas rendah (LL < 50\%), ternyata sudah memenuhi syarat sebagai tanah dasar jalan $(\mathrm{PI}=7,04 \%<10 \%$ dan $\mathrm{CBR}=11,33 \%>6 \%)$ dan memenuhi syarat distabilisasi butimen (PI <30\%).

Selanjutnya dalam usaha memperbaiki sifat fisiknya, tak ada salahnya bila diberi tambahan butimen MC-250, agar diperoleh lapisan perkerasan di atasnya yang lebih tipis. Akan tetapi, ternyata melalui test Atterberg terhadap tanah yang telah distabilisasi butimen, sesuai Tabel 3 nampak nilai batas cair (LL), semakin banyak kadar bitumen, semakin menurunkan nilai LL. Nilai tertinggi pada kadar aspal $2 \%$ dengan $\mathrm{LL}=$ $30,70 \%$ lebih besar dari sebelum distabilisasi $\mathrm{LL}=23,50 \%$ Kemudian harga Indeks Plastisitas (PI), semakin banyak kadar butimen, semakin memperbesar harga PI. Kadar butimen yang tepat untuk memenuhi persyaratan tanah dasar, adalah $2 \%$ harga PI $=9,85 \%<\mathrm{PI}$ maximum $=10 \%$ walaupun masih lebih besar dan PI tanah asli 7,04\%

Melalui test proktor, sesuai Tabel 3, nampak bahwa kadar butimen yang tepat adalah $2 \%$ karena pada kadar tersebut nilai Wc optimum adalah paling kecil $(12,12 \%)$ dari $\gamma$ dry mempunyai nilai terbesar (1,96 gr/ cc).

Melalui test CBR, sesuai Tabel 4 nampak bahwa pada kondisi kering, semakin banyak pukulan, semakin mempertinggi harga CBR. Kemudian nampak pula bahwa penambahan butimen, semakin memperkecil harga CBR. $\mathrm{Hal}$ ini dimungkinkan karena dengan penambahan butimen, campuran menjadi lebih plastis. Pemilihan kadar butimen 2\% masih diperoleh harga $\mathrm{CBR}>\mathrm{CBR}$ minimum $=$
6\% yang memenuhi persyaratan tanah dasar jalan. Akan tetapi pada kondisi basah, kadar butimen yang paling tepat adalah $3 \%$ dengan nilai CBR > CBR minimum $=6 \%$ yang memenuhi persyaratan untuk tanah dasar jalan atau dipilih kadar butimen $2 \%$ dengan 30 pukulan.

\section{KESIMPULAN}

Berdasarkan pembahasan sebelumnya dapat disimpulkan sebagai berikut:

- Tanah Pandaan Jawa Timur memenuhi syarat sebagai tanah dasar jalan karena tanah asli (sebelum distabilisasi) mempunyai harga $\mathrm{PI}=7,04 \%<\mathrm{PI}$ maximum $=10 \%$ dan harga $C B R=11,33 \%$ $>$ CBR minimum $=6 \%$

- Tanah Pandaan Jawa Timur, memenuhi persyaratan distabilisasi butimen karena harga $\mathrm{PI}=7,04 \%<\mathrm{PI}=12 \%, \mathrm{LL}=23,50 \%<$ $\mathrm{LL}=30 \%$ dari prosentase lolos saringan no. $200=41,84 \%<50 \%$

- Tanah asli Pandaan setelah dicampur butimen, nilai batas cair (LL) semakin besar, pada $2 \%$ kadar butimen diperoleh $\mathrm{LL}=30,70 \%>\mathrm{LL}=23,50 \%$ kondisi asli. Nilai Indeks Plastisitas (PI), semakin besar kadar butimen, Harga PI semakin besar, pada $2 \%$ kadar butimen diperoleh $\mathrm{PI}=9,85 \%>\mathrm{PI}=7,04 \%$ kondisi asli. Walaupun $\mathrm{PI}$ tersebut $<\mathrm{PI}$ maximum = 10\% sebagai syarat tanah dasar asli.

- Tanah Pandaan setelah distabilisasi butimen, mempunyai harga $\mathrm{Wc}_{\text {opt }}=$ $12,12 \%$ dengan $\gamma d=1,96 \mathrm{gr} / \mathrm{cc}$ pada $2 \%$ kadar butimen.

- Tanah Pandaan, setelah distabilisasi butimen, harga CBR semakin turun, pada kondisi kering, dan pada kadar butimen $2 \%$ menghasilkan harga CBR yang maximum (lihat Tabel 4). Penurunan harga ini disebabkan campuran menjadi lebih plastis, sehubungan penambahan butimen tersebut. Tetapi pada kondisi basah, kadar butimen yang paling tepat adalah 3\% dengan harga CBR $=26 \%>$ CBR minimum $=6 \%$ atau kadar butimen $2 \%$ pada 30 pukulan dengan harga CBR = $24 \%>$ CBR minimum $=6 \%$ yang semuanya memenuhi persyaratan tanah dasar jalan. 
J urnal APLIKASI

\section{DAFTAR ACUAN}

Acuan yang dipakai untuk penulisan paper ini antara lain:

1. Departemen PU, Direktorat J enderal Bina Marga, "Spesifikasi Umum".

2. National Association of Australian State Road Authorities (1970), "Guide Stabilization in Road Works".
3. Sukirman, S (1993), "Perkerasan Lentur J alan Raya", Penerbit Nova Bandung.

4. Soekiswo, Hary S dan Heru S. (1987), "Stabilisasi Tanah dengan Butimen", Tugas Akhir mahasiswa LPPU ITS.

5. Punmia (1981), "Soil Mechanics and Foundations", Publisher Raj inder Kumar Jain.

\section{Halaman 4 J urnal APLIKASI: Media Informasi \& Komunikasi Aplikasi Teknik Sipil Terkini}

